\title{
Reproductive potential of caucasian clover at four locations within New Zealand
}

\author{
R.G. THOMAS ${ }^{1}$, K.H. WIDDUP ${ }^{2}$, K. PANKHURST ${ }^{3}$ and D. RYAN ${ }^{4}$ \\ AgResearch \\ ${ }^{1}$ Grasslands Research Centre, PB 11008, Palmerston North \\ ${ }^{2}$ Canterbury Agriculture and Science Centre, PO Box 60, Lincoln \\ ${ }^{3} P O$ Box 23, Kerikeri \\ ${ }^{4}$ PO Box 342, Gore
}

\begin{abstract}
Seedlings of KZ2 caucasian clover (Trifolium ambiguum) were grown at 4 sites within New Zealand (Kerikeri $36^{\circ} \mathrm{S}$, Palmerston North $40^{\circ} \mathrm{S}$, Lincoln $43^{\circ} \mathrm{S}$ and Gore $46^{\circ} \mathrm{S}$ ) where they received natural daylight and temperatures during 1997. Northernmost plants produced more vegetative primary crown shoot buds than southernmost. In the first growing season numbers of flowering shoots formed per plant were: K 17.9, P 10.0, L 10.2 and $G$ 5.7. In spring of the second growing season, mean numbers of primary crown flowering shoots per plant at peak flowering in December 1997 were: K 19, P 30, L 55, G 20. Fewer flowering shoots formed at upturned rhizome tips. Daylength was not the major factor controlling flowering, the results instead supporting the hypothesis that low temperatures provided the main flowering stimulus. Lincoln was the best of the four locations overall for flowering shoot production. Fewer flowering shoots at Gore probably resulted from slower growth in cooler conditions. Poorer flowering at Kerikeri in the second season might have resulted from the warmer northern winter or been linked to the overproduction of vegetative buds in the first season. Stronger flowering at Kerikeri during the first season raises the possibility, though, of growing caucasian clover as an annual crop for seed production in Northland if sown early in spring.
\end{abstract}

Keywords: caucasian clover, daylength, flowering, low temperature, seed production, Trifolium ambiguum

\section{Introduction}

Caucasian clover (Trifolium ambiguum) is a perennial species that has a reputation as a poor seed producer (Widdup et al. 1996). Understanding the causes of this requires an understanding of the pattern of growth of the plant as is outlined in Figure 1. From autumn or spring sowing, seedlings develop a primary crown bearing lateral buds which either remain as above-ground vegetative crown shoot buds or, if positioned below the soil surface, grow out into underground rhizomes. In the first season of spring-summer growth (here referred to as Season I) some of the above-ground crown shoot buds initiate flower-head buds and grow up into semierect elongated flowering shoots each of which produces several flower-heads over the ensuing weeks. The crop of flower-heads in Season I is relatively small.

Those above-ground crown buds that remain nonflowering produce a second generation of additional vegetative shoot buds, some of which elongate and flower in the second growing season (Season II), giving a much higher yield of flower-heads and seed-heads than in Season I. Concomitant with the flowering during Season I, many rhizome tips become upturned. A varying proportion of these develop into secondary crowns which form above-ground vegetative shoot buds capable of flowering in Season II and thereby contributing to the increased seed yield in that season. Other rhizomes branch underground, massively increasing the volume of plant material in the soil, and the upturned tips of some of these develop into further secondary crowns with the ability to flower.

Towards the end of Season II, the primary crowns weaken and they eventually die in Season III or IV. The plant shoot biomass at this stage becomes represented solely by a mix of underground rhizomes, some of which develop leafy upturned tips and only a few of which grow into further secondary crowns. At this stage the number of flowering shoots produced per season declines and seed yields drop.

The initiation of flower-heads in caucasian clover is influenced by two major environmental factors: photoperiod and temperature. Under warm conditions caucasian clover has been shown by Kannenburg \& Elliot (1962) to be a long-day plant. This has been confirmed by Thomas (unpublished) who also found that flowering in short days is also induced by low temperature. It might thus be expected that within New Zealand flower-head production would be best in southern regions, experiencing both the longest summer daylengths and coolest winters, and poorest in northern regions with the shortest summer daylengths and 
Figure 1 Sequence of development of primary crowns, rhizome systems and secondary crowns in caucasian clover over the first three growing seasons following seed germination in spring. $\mathrm{FL}=$ flowering shoots.

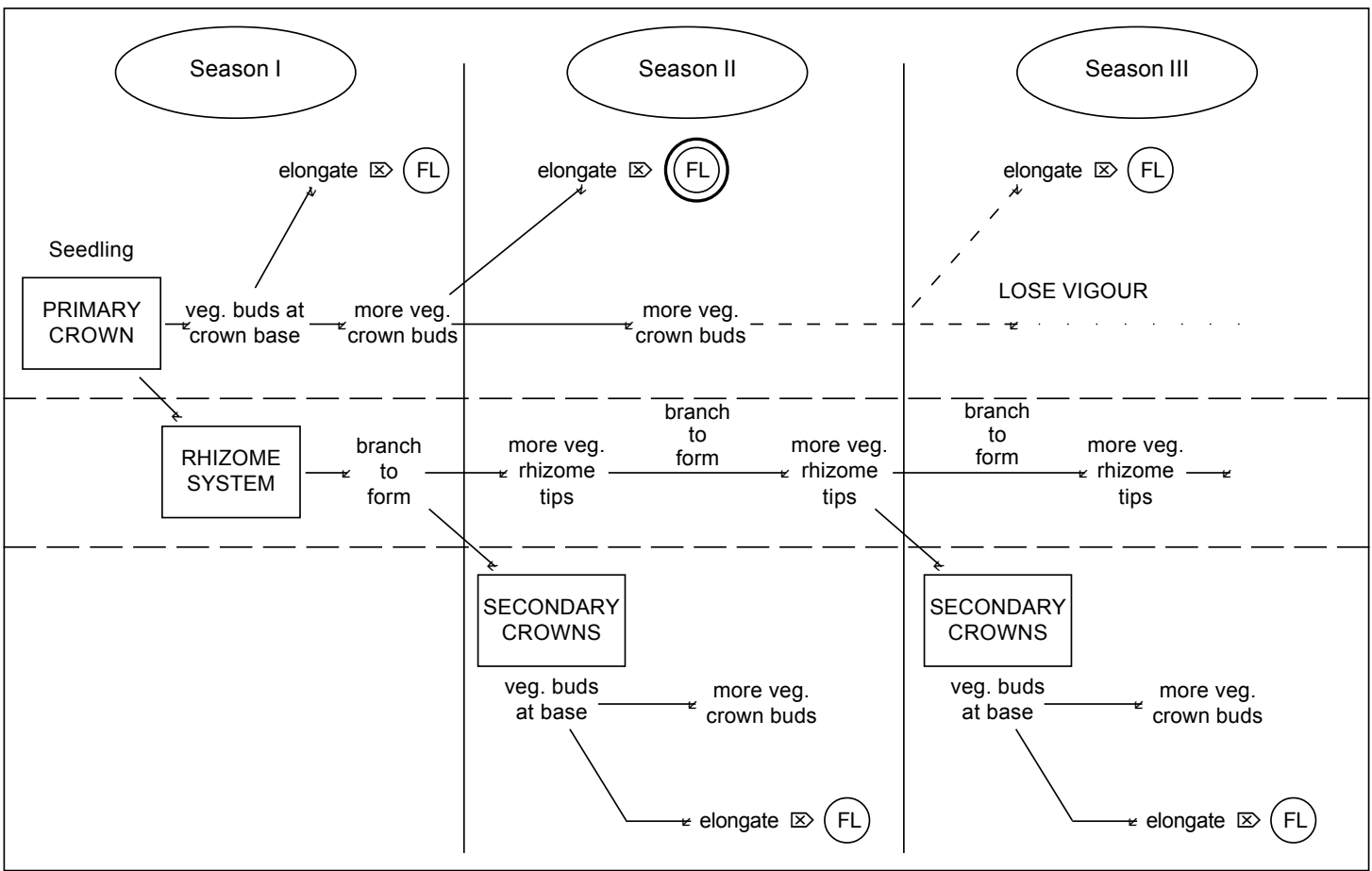

warmest winters. The present investigation was undertaken to test this hypothesis with a view to determining the theoretically best latitudinal location for flower-head production.

\section{Materials and methods}

Seeds of KZ2 caucasian clover, a selection from cv. Monaro, were sown at Lincoln, Canterbury, in August 1996 and 100 seedlings grown in root trainers in natural photoperiods in an unheated glasshouse. In mid October, when plants were two months old, they were moved into an unheated shade house until mid November when they were transferred into the open. Seedlings were inoculated with Rhizobium in early December and groups of 25 were sent to each of the following locations on 9 December 1996: Kerikeri $36^{\circ} \mathrm{S}$, Palmerston North $40^{\circ} \mathrm{S}$, and Gore $46^{\circ} \mathrm{S}$. One group of 25 seedlings remained at Lincoln $43^{\circ} \mathrm{S}$. At these sites, seedlings were planted into identical 5-litre plastic pots filled with a standard Yates potting mix containing slowrelease nutrient pellets and grown outside at natural daylengths and temperatures. Pots were watered regularly to prevent drying out. In early April 1997 the plants were repotted into larger patio tubs where they remained until February 1998. Temperatures during the period of the experiment are shown in Table 1. Numbers of flowering shoots bearing at least one fully

Table 1 Mean monthly air maximum and grass minimum temperatures $\left({ }^{\circ} \mathrm{C}\right)$ at each of the four sites over the period of the experiment (January to December 1997). [Data supplied by NIWA].

\begin{tabular}{|c|c|c|c|c|c|c|c|c|c|c|c|c|c|}
\hline Month & & $\mathrm{J}$ & $\mathrm{F}$ & $M$ & $A$ & $M$ & $\mathrm{~J}$ & $J$ & $A$ & $\mathrm{~S}$ & $\mathrm{O}$ & $\mathrm{N}$ & $\mathrm{D}$ \\
\hline & Max & - & - & 22.8 & 20.5 & 18.8 & 16.3 & 15.6 & 15.3 & 17.0 & 19.0 & 22.0 & 22.9 \\
\hline Kerikeri & Min & - & - & 10.6 & 6.5 & 8.1 & 3.8 & 1.6 & 2.6 & 5.9 & 6.4 & 8.7 & 12.3 \\
\hline Palmerston & Max & 21.0 & 22.8 & 19.9 & 17.3 & 17.2 & 13.1 & 12.7 & 13.1 & 14.4 & 16.2 & 18.1 & 20.4 \\
\hline North & Min & 9.2 & 11.3 & 10.3 & 5.0 & 5.8 & 0.8 & -0.1 & 2.8 & 3.9 & 5.7 & 8.4 & 8.9 \\
\hline & Max & 19.1 & 21.2 & 18.1 & 16.7 & 15.0 & 11.6 & 11.3 & 12.6 & 12.7 & 18.1 & 21.1 & 21.5 \\
\hline Lincoln & Min & 9.0 & 10.7 & 7.1 & 3.6 & 3.2 & -0.8 & -2.5 & 0.1 & 1.8 & 3.8 & 5.4 & 6.9 \\
\hline & Max & 18.4 & 18.1 & 16.0 & 14.3 & 12.1 & 9.2 & 8.8 & 10.3 & 11.3 & 14.8 & 15.3 & 16.7 \\
\hline Gore & Min & 7.9 & 8.7 & 5.3 & 4.2 & 2.8 & 1.9 & -0.6 & 0.2 & 1.3 & 4.0 & 4.8 & 6.5 \\
\hline
\end{tabular}


open white floret, vegetative crown shoot buds and upturned leafy rhizome tips were recorded at intervals from January 1997 to January 1998.

\section{Results}

In Season I all flowering shoots developed from initially vegetative primary crown shoot buds, none from upturned rhizome tips (Figure 2). White florets appeared on the first flowering shoots in mid February and the number of flowering shoots bearing white florets increased steadily through to the end of March at Kerikeri. The rate of appearance of flowering shoots was slower at Palmerston North and Lincoln, tailing off as at Kerikeri at the end of March. At Gore peak flowering was reached a month earlier, by early March, and final flowering stem numbers were much lower. By 2 April the mean numbers of blossoming shoots produced per plant were 17.9 at Kerikeri, 10 and 10.2 respectively at Palmerston North and Lincoln, and 5.7 at Gore (Table 2). At this stage the number of nonelongated vegetative primary crown buds per plant at each site was also recorded as differing very greatly
(Table 2) from a mean of 52.2 at Kerikeri to means of 4.7, 9.5 and 9.6 respectively at Palmerston North, Lincoln and Gore. During this first growing season plants produced horizontal underground rhizomes which grew outwards to reach pot margins where their tips ultimately turned upwards to form vegetative shoots. As with the numbers of vegetative primary crown buds produced, the number of upturned vegetative rhizome tips was greater at the North Island sites than in the South Island (Table 2).

Table 2 Mean numbers of flowering shoots, primary crown vegetative shoot buds and leafy upturned rhizome tips at pot margins at the end of Season I (2 April 1997).

\begin{tabular}{lccc}
\hline & $\begin{array}{c}\text { No. of } \\
\text { flowering } \\
\text { shoots }\end{array}$ & $\begin{array}{c}\text { No. of crown } \\
\text { vegetative } \\
\text { shoot buds }\end{array}$ & $\begin{array}{c}\text { No. of } \\
\text { upturned } \\
\text { rhizome tips }\end{array}$ \\
\hline Kerikeri & 17.9 & 52.2 & 5.0 \\
Palmerston North & 10.0 & 4.7 & 6.9 \\
Lincoln & 10.2 & 9.5 & 2.6 \\
Gore & 5.7 & 9.6 & 0.4 \\
LSD (5\%) & 3.6 & 9.9 & 2.2 \\
\hline
\end{tabular}

Figure 2 Mean numbers of flowering shoots developed during Season I (January to April 1997) and Season II (September 1997 to

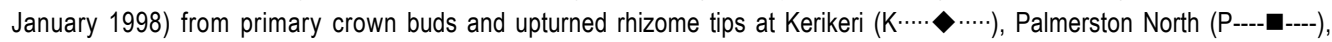
Lincoln (L ..............) and Gore (G-•- - ). 
In Season II, flowering shoots were produced both from initially vegetative primary crown shoot buds and from secondary crowns formed from rhizome tips at pot margins (Figure 2). The appearance of white florets was markedly earlier at Kerikeri than at the other sites, the number of blossoming shoots per primary crown averaging 7 per plant at Kerikeri on 27 September when plants at Palmerston North and Lincoln averaged only about one blossoming shoot. By interpolation on the graph in Figure 2, it can be seen that the same number of blossoming shoots per primary crown was not reached at Gore until about 6 weeks later (7 November). Although flowering stem production started so much earlier at Kerikeri, the final flowering stem number attained on primary crowns was much lower (20) at Kerikeri than at Lincoln (60), Palmerston North and Lincoln being intermediate at 33 and 27 respectively. Appearance of flowering shoots on secondary rhizome crowns began later (early November) than on the primary crowns and contributed less to the overall yield. Again, plants at Lincoln produced the highest number of secondary crown flowering shoots (13 on 23 December) and those at Palmerston North and Gore fewer ( 8 and 5.5 respectively on the same date). No flowering was recorded from secondary rhizome tip crowns at Kerikeri.

\section{Discussion}

Many factors influence seed production in a clover crop but of these the primary component of yield is flower head density (Clifford 1980; Thomas 1996) which in turn in caucasian clover depends on the number of flowering shoots per $\mathrm{m}^{2}$. This study was therefore aimed at determining which location within New Zealand has the best potential for flowering shoot formation. In caucasian clover the total number of flowering shoots is determined by:

1. the number of vegetative shoot buds present at the start of flower-promoting conditions,

2. the strength of the environmental stimulus to flower (e.g., the daylength or intensity of cold), and

3. the ability of vegetative shoot buds to respond to the flowering stimulus.

In Season II, plants at all sites behaved as reported by previous workers (Kannenberg \& Elliot 1962; Townsend 1970; Stewart 1979; Dear \& Zorin 1985; Daly et al. 1993; Efendi 1993; Widdup et al. 1996), exhibiting peak flowering in spring. Flowering time at each site was directly related to spring temperatures (Table 1), being earliest at the warmest site (Kerikeri) where spring growth would have been fastest and latest at the coolest (Gore) where spring growth would have been slowest. The earliness of flowering in spring and the progressive delay in onset of flowering from north to south strongly suggest that long photoperiods are not a cause of peak flowering in spring in plants overwintered at natural field temperatures.

The number of vegetative shoot buds present in the preceding autumn did not appear to be directly correlated with flowering vigour either. The mean number of flowering shoots per plant was by far the highest at Lincoln (60) and lowest at Kerikeri (20), despite the fact that the number of vegetative shoot buds present on primary crowns at Kerikeri in the previous autumn was recorded as being about 10 times higher than at other sites (Table 2). This suggests that the poor flowering performance at Kerikeri in Season II must have been the result either of a weak environmental stimulus to flower (the maximum and minimum temperatures from May to September averaging about $4^{\circ} \mathrm{C}$ more at Kerikeri than at Lincoln (Table 1)) or the inability of the buds to respond to the flowering stimulus (perhaps as a result of overcrowding). These two possibilities are currently under investigation.

In contrast to the pattern of flowering in Season II, the flowering behaviour of young plants in Season I was quite unexpected and out of keeping with previous reports. Although the young plants were exposed to natural cool conditions at Lincoln from August onwards, they did not begin to flower until late January (Figure 2) and flowering did not peak until March. This suggests that the plants were perhaps insensitive to cold conditions at a young juvenile stage and that in the warmer summer conditions from December onwards flowering might have been a response to long photoperiods. As summer turned to autumn, growth and flowering slowed sooner at the cooler more southern sites. At Kerikeri, where conditions stayed warmer for longest, plants produced nearly twice as many flowering shoots as elsewhere (17.9 vs 10.0, 10.2, and 5.7 at Palmerston North, Lincoln and Gore respectively; Figure 2).

Overall these results demonstrate clearly that, once the plants were established in Season II, Lincoln yielded the highest numbers of flowering shoots and Canterbury is thus supported as the most suitable location for a perennial crop. Further south, at Gore, longer, cooler, spring conditions slowed the rate of flowering shoot growth and progression to blossoming. Further north, at Kerikeri, flowering shoot numbers were markedly fewer. Even so, because flowering shoot production was highest at Kerikeri in Season I, there remains a possibility that Kerikeri might be a suitable location for growing caucasian clover as an annual crop for seed production and experiments to test the feasibility of this suggestion are in progress. 


\section{ACKNOWLEDGEMENTS}

The authors wish to thank Michael Norris of Wrightson Ltd for supplying the seedlings of KZ2 to use in this experiment and Bruce Cooper for technical assistance/ guidance at Kerikeri.

\section{REFERENCES}

Clifford, P.T.P. 1980. Research in white clover seed production. In: Lancashire, J.A. (ed.) Herbage Seed Production. New Zealand Grassland Association. Grassland Research and Practice Series No. 1: 6467.

Daly, G.T.; Gurung, J.; Lucas, R.J. 1993. Stand age and closing date effects on seed yield of caucasian and zigzag clover cultivars. Proceedings of the XVII International Grassland Congress: 1664-1666.

Dear, B.S.; Zorin, M. 1985. Persistence and productivity of Trifolium ambiguum M. Bieb. (Caucasian clover) in a high altitude region of south-eastern Australia. Australian journal of experimental agriculture 25: 124-132.

Efendi, F. 1993. A study of vegetative and reproductive development in Caucasian clover (Trifolium ambiguum M. Bieb.) cv. Monaro. MSc thesis, Massey University.
Kannenberg, L.W.; Elliot, F.C. 1962. Ploidy in Trifolium ambiguum M. Bieb. in relation to some morphological and physiological characters. Crop science 2: 378-382.

Stewart, A.V. 1979. Genetic evaluation of Trifolium ambiguum. MSc thesis, Lincoln College, University of Canterbury.

Thomas, R.G. 1996. Maximising seed production potential in white clover: factors influencing seed set per floret. Agronomy Society of New Zealand Special Publication No. 11/Grassland Research and Practice Series No. 6: 41-44.

Townsend, C.E. 1970. Phenotypic diversity for agronomic characters and frequency of self-compatible plants in Trifolium ambiguum. Canadian journal of plant science 50: 331-338.

Widdup, K.H.; Knight, T.L.; Hunt, L.H. 1996. Genetic variation for seed yield in caucasian clover. Proceedings of the New Zealand Grassland Association 58: 189-194. 
